\title{
ANALISIS BIAYA OPERASIONAL KENDARAAN BUS MICRO PO. TEGUH RAHAYU TRAYEK PURBALINGGA-BOBOTSARI
}

\author{
Sulfah Anjarwati ${ }^{1}$, Tri Adi Saputro ${ }^{2}$ \\ Program Studi S1 Teknik Sipil, Universitas Muhammadiyah Purwokerto \\ Fakultas Teknik dan Sains, Universitas Muhammadiyah Purwokerto
}

\begin{tabular}{l} 
Informasi Makalah \\
\hline Dikirim, 30 Maret 2021 \\
Direvisi, 06 April 2021 \\
Diterima, 9 April 2021 \\
\hline
\end{tabular}

\section{Kata Kunci:}

Computer Vision

Similiarity

Euclidean Distance

Grayscale

Histogram

\begin{abstract}
INTISARI
Angkutan umum merupakan salah satu moda transportasi yang masih menjadi pilihan masyarakat di Purbalingga. Satu diantaranya adalah PO. Teguh Rahayu yang melayani rute Terminal Purbalingga - Bobotsari. Penentuan besaran tarif angkutan membutuhkan penanganan dan kebijakan yang arif. Karena harus dapat menjembatani kepentingan pengguna jasa dan pengelola jasa angkutan umum. Maka dari itu dilakukan penelitian mengenai tarif berdasarkan Biaya Operasional Kendaraan untuk mengetahui tarif yang tepat. Metode pengumpulan data dengan melakukan survey penumpang dan wawancara terhadap Operator PO. Teguh Rahayu untuk mengetahui biaya operasional kendaraan micro bus. Didapatkan hasil BOK rata - rata sebesar Rp. 5.906,91/ Orang-trip. Untuk perhitungan tarif maksimal diperoleh sebesar Rp 6.302,04 dan perhitungan tarif minimal diperoleh Rp 3.428,35. Namun tarif yang ada di lapangan dimana tarif ditetapkan adalah Rp. 5000/orang-trip, untuk satu kali perjalanan dengan jarak tempuh $11 \mathrm{Km}$. Berdasarkan perhitungan tarif Bus PO. Teguh Rahayu trayek terminal Purbalingga - Bobotsari didapat harga tarif lapangan mendekati posisi tarif perhitungan biaya operasional kendaraan. Hal ini menunjukan hasil analisis tarif berdasarkan biaya operasional kendaraan dengan tarif sebenarnya masih sesuai.
\end{abstract}

\section{Keyword:}

Computer Vision

Similiarity

Euclidean Distance

Grayscale

Histogram

\begin{abstract}
Along with the increasingly rapid development of telecommunications technology, adequate telecommunications equipment is needed. In order to overcome interference obtained from geographical conditions, it is necessary to design a very mature microwave link.In this paper a microwave link design is used using antenna point to point configuration, space diversity and non diversity at sites in the same area. The design was carried out in the Thousand Islands area, precisely Pari island with south latitude coordinates 5 - 51'29.38 "S and east longitude coordinates $106^{\circ} 37$ '3.48" E and Pramuka Island in south latitude coordinates $5^{\circ} 44^{\prime} 47.15$ "S and east longitude coordinates $106^{\circ} 36^{\prime} 48.71$ "E. Microwave link design using PathLoss 5.0 software.Based on the design using Pathloss 5.0 using the point to point configuration of the annual rain + multipath availability value that is $99.95682 \%$, when using the non diversity configuration the resulting annual rain + multipath availability value is $99.91683 \%$ and when using the space diversity configuration The resulting annual rain + multipath availability value is $99.90859 \%$. The three available availability values meet the ideal conditions because the value is above $99 \%$, the value obtained at the point to point configuration gets a better availability value.
\end{abstract}

\section{Korespondensi Penulis:}

Sulfah Anjarwati

Program Studi Teknik Sipil

Universitas Muhammadiyah Purwokerto

JL. Raya Dukuhwaluh Purwokerto, 53182 
Email: sulfahanjarwati75@gmail.com

\section{PENDAHULUAN}

Angkutan umum berkembang semakin pesat. Hal ini disebabkan oleh kemajuan teknologi dan taraf hidup masyarakat yang semakin meningkat. Seperti Bus Rapid Trasit, Ojek Onlin dan lain lain, yang menjadikan transportasi angkutan umum semakin praktis dan relatif murah. Sehingga menimbulkan persaingan ketat bagi para pelaku usaha transportasi darat khususnya angkutan umum seperti bus micro yang berimbas terhadap besarnya tarif

Pemerintah yang berperan sebagai penengah antara operator/pengusaha angkutan dan masyarakat membutuhkan pembahasan yang cukup panjang dalam penentuan tarif ini. Bila mengedepankan tuntutan masyarakat pengguna jasa semata tanpa menghiraukan kepentingan operator/pengusaha angkutan adalah keputusan yang tidak bijaksana. Namun bila hanya berpihak pada kepentingan (private profit) operator/pengusaha angkutan, maka masyarakat yang akan menanggung bebannya [1].

Tarif angkutan umum yang murah menjadi suatu faktor penentu pilihan penumpang terhadap angkutan umum. Tarif menjadi faktor yang penting dalam mendapatkan pelayanan dan fasilitas yang diberikan oleh karena itu penentuan tarif dan kebijakannya dari suatu angkutan umum merupakan elemen paling penting dalam operasi bus dan mempengaruhi sikap penumpang dalam melakukan perjalanan [2]. Bus PO Teguh Rahayu merupakan salah satu bus yang menyediakan jasa angkutan umum penumpang dengan dengan trayek terminal purbalingga - bobotsari dengan jarak tempuh kurang lebih $11 \mathrm{~km}$ setiap trip dan frekuensi pelayanan 3 trip perhari pulang-pergi. Berdasarkan latar belakang yang ada maka peneliti ingin mengetahui berapa besar Biaya Operasional Kendaraan angkutan umum Micro Bus PO Teguh Rahayu.

\section{METHODS}

Metode pengumpulan data dalam penelitian menggunakan data primer dan data sekunder. Pelaksanaan survei untuk mendapatkan data primer dilakukan dalam waktu 2 hari dalam seminggu untuk mengetahui perbedaan banyaknya penumpang pada weekdays dan weekend. Pada hari Senin \& minggu dengan trayek Terminal Purbalingga-Bobotsari. Survei on Board, yaitu survei terhadap kendaraan (angkutan) secara fisik, dan pengamatan terhadap kinerja pelayanan angkutan umum meliputi rute, panjang rute, jumlah angkutan, jumlah penumpang, kecepatan perjalanan, dan faktor muat (load factor) secara langsung dengan pengamat berada dalam kendaraan. Survei Investigasi, yaitu wawancara langsung terhadap informan. Yaitu pada pihak sopir untuk memperoleh data Biaya Operasi Kendaraan. Berdasarkan berbagai pengamatan di lapangan untuk mendapatkan data aspek operasional angkutan umum yang telah dilakukan maupun berdasarkan dari berbagai acuan, maka dalam melakukan survei ini dilakukan dengan mengikuti kendaraan dari rute asal ke rute akhir. Pengambilan data jumlah penumpang atau banyaknya penumpang yang naik/turun pada suatu kendaraan dilakukan dengan mencatat jumlah penumpang yang naik/turun dan jumlah penumpang diatas kendaraan sepanjang trayek perjalanan yang beroperasi pada hari survei [3]. Dalam usaha mencatat jumlah penumpang dilapangan dilakukan dengan cara sebagai berikut: seorang petugas diberikan tugas untuk mencatat satu kendaraan. Setiap penumpang yang naik, maka jumlah yang berada didalam kendaraan dicatat pada form yang telah disiapkan.

Pengambilan data waktu tempuh kendaraan di lapangan dilakukan dengan mencatat waktu mulai berangkat dari rute asal dan waktu tiba pada rute akhir. Total waktu yang digunakan untuk melayani rute dalam sekali jalan, termasuk tundaan, waktu berhenti untuk menaikkan dan menurunkan penumpang. Pada survei waktu tempuh dilakukan dengan cara manual dan alat yang dipakai adalah jam tangan yang dibawa oleh pencatat. Tata cara pengambilan data waktu tempuh dilakukan sebagai berikut: Petugas mencatat waktu berangkat tepat pada saat kendaraan mulai bergerak meninggalkan rute awal dan mencatat waktu pada saat kendaraan tiba di rute akhir. Waktu yang didapat (waktu tempuh) langsung dicatat pada form yang tersedia, selanjutnya dilakukan pencatatan yang sama untuk semua kendaraan yang dinaiki oleh si petugas.

Sebelum dilakukan survei ke lapangan terlebih dahulu dilaksanakan pengumpulan data sekunder seperti: Tarif dari organda angkutan antar kota serta rute yang dilewati diperoleh dari Dinas Perhubungan Kabupaten Purbalingga, data izin trayek dan izin usaha yang diperoleh dari Dinas Perizinan Terpadu Kabupaten Purbalingga. 


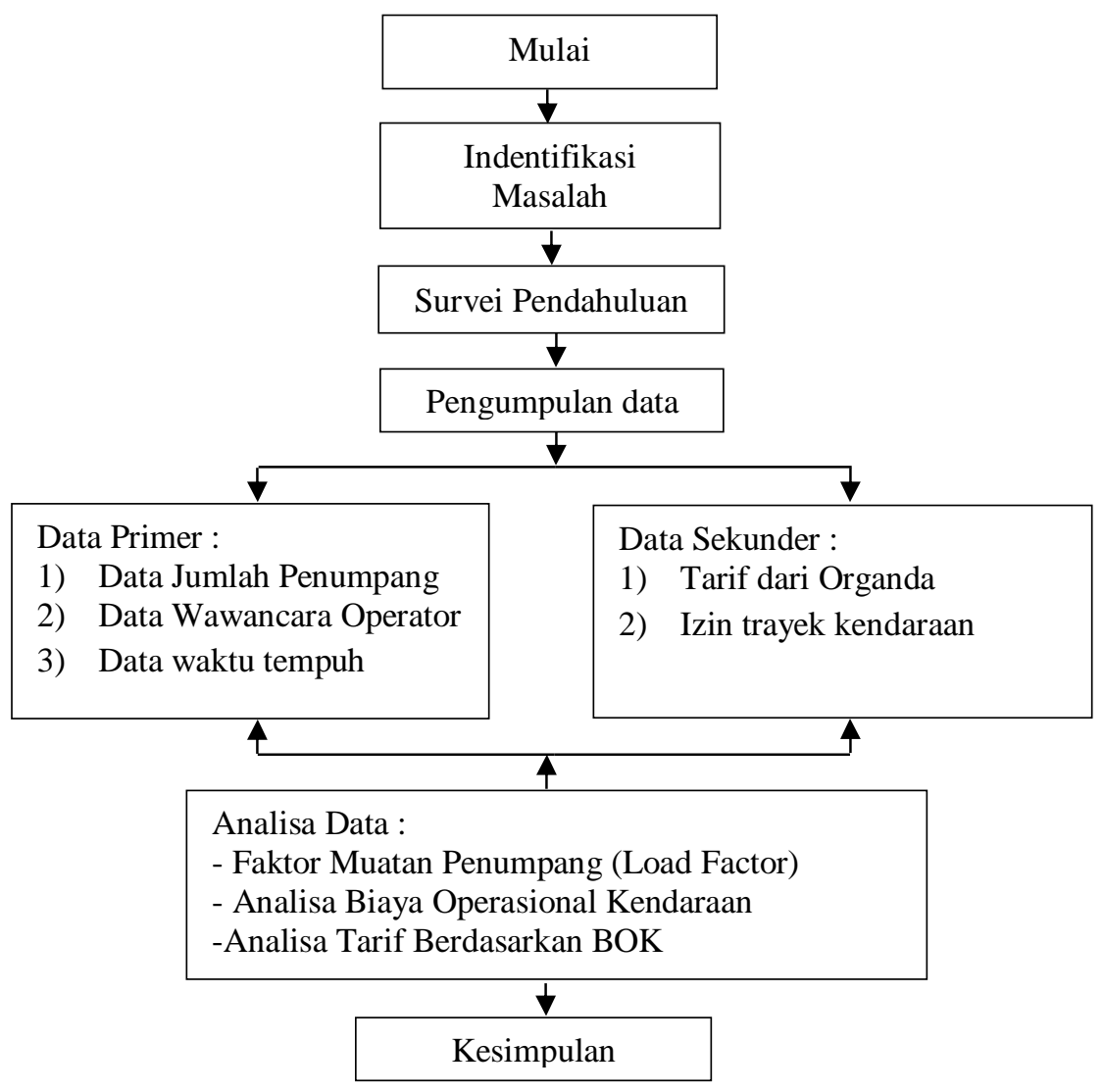

Gambar 1. Bagan Alir Penelitian

\section{HASIL DAN PEMBAHASAN (10 PT)}

A. Faktor Muatan Penumpang (Load Factor)

Faktor muatan penumpang adalah sebagai perbandingan antara banyaknya penumpang per jarak dengan kapasitas tempat duduk angkutan umum yang tersedia [4]. Faktor muatan penumpang untuk keberangkatan dari Terminal purbalingga. setiap hari survei diperoleh dengan cara membagikan jumlah penumpang setiap sampel dengan kapasitas tempat duduk yang tersedia. Kemudian dihitung faktor muatan penumpang rata-rata untuk setiap hari survei.

Tabel 1. Load Factor Micro Bus PO. Teguh Rahayu

TRAYEK TERMINAL PURBALINGGA - BOBOTSARI

\begin{tabular}{|c|c|c|c|c|c|c|c|c|c|c|c|c|c|c|}
\hline \multirow[t]{2}{*}{ HARI } & \multicolumn{3}{|c|}{$\begin{array}{c}\text { TERMINAL } \\
\text { PURBALINGGA }\end{array}$} & \multicolumn{3}{|c|}{ SIMPANG MIRA } & \multicolumn{3}{|c|}{$\begin{array}{l}\text { SIMPANG } \\
\text { SIRONGGE }\end{array}$} & \multicolumn{3}{|c|}{ BOBOTSARI } & \multirow[t]{2}{*}{ Kapasitas } & \multirow[t]{2}{*}{$\begin{array}{c}\text { Load } \\
\text { Faktor }\end{array}$} \\
\hline & NAIK & TURUN & JUMLAH & NAIK & $\underset{\mathbf{N}}{\text { TURU }}$ & JUMLAH & NAIK & TURUN & JUMLAH & NAIK & TURUN & JUMLAH & & \\
\hline $\begin{array}{c}\text { Minggu } \\
10 / 01 / \\
2021\end{array}$ & 14 & - & 14 & 2 & 5 & 11 & 7 & 4 & 14 & - & 14 & 14 & 18 & $54,4 \%$ \\
\hline $\begin{array}{l}\text { Senin } \\
11 / 01 \\
/ 2021\end{array}$ & 9 & - & 9 & 4 & 3 & 10 & 8 & 2 & 16 & - & 16 & 16 & 18 & $62,2 \%$ \\
\hline
\end{tabular}




\section{A. Biaya Tetap (Fix Cost)}

1. Penyusutan Kendaraan

Harga kendaraan $=$ Rp. $374.500 .000 ;$ Nilai Residu $=20 \%$ : Masa penyusutan $=5$ Tahun;

Penyusutan kendaraan $=\frac{\text { Harga Kendaraan - Nhat residu }}{\mathrm{Km} \text { selama setahun } \mathrm{X} \text { Maga Penyusutant }}=\mathrm{Rp} 2.702 / \mathrm{km}$

2. Pajak Kendaraan

Biaya pajak $=\operatorname{Rp} 402.500 / \mathrm{kend} /$ tahun $; \mathrm{Km}$ tempuh $/$ tahun $=22.176 \mathrm{~km} / \mathrm{tahun}$

Pajak Kendaraan $=\frac{\text { Biaya Pajak }}{\mathrm{km}-\text { tempulh } / \text { thn }}=$ Rp. $18,15 / \mathrm{km}$

3. Biaya Awak Kendaraan

Gaji supir $=$ Rp 100.000/hari; Km tempuh/hari $=66$ km/hari

Biaya Awak Kendaraan $==\operatorname{Rp} 1515,15 / \mathrm{Km}$

\section{B. Biaya Berubah (Variable Cost)}

1. Bahan Bakar Minyak (BBM)

Harga solar $=$ Rp 5100/liter $;$ Pemakaian $\mathrm{BBM}=0,891$ liter $/ \mathrm{km} ; \mathrm{Km}$ tempuh $/$ hari $=66 \mathrm{~km}$

Biaya $\mathrm{BBM}=($ Pemakaian $\mathrm{BBM}$ per hari $) /(\mathrm{km}$-tempuh per hari $)==$ Rp. $1.515,15 / \mathrm{km}$

2. Ban

Jumlah pemakaian ban $=4$ buah ; Harga ban/buah = Rp. $940.000 \mathrm{Km}$; Daya tahan ban $=22.176 \mathrm{~km}$ Imlh. Pemakaian Ban x Harga Ban/buah

Biaya $\operatorname{Ban}=\quad$ Krndaya tahan ban $=R p 169,55 / \mathrm{km}$

3. Servis Kecil

Oli mesin = 10 liter x Rp $26.500=\operatorname{Rp} 265.000$; Gemuk =0,5 kg x Rp $36.000=$ Rp. 18.000

Minyak rem $=0.3$ liter $x$ Rp $90.000=$ Rp. $27.000 ;$ Upah servis = Rp. $50.000 ;$ Jumlah total = Rp 360.000

Servis Kecil $=\frac{\text { Biaga servis kedl }}{7392 \mathrm{~km}}=\mathrm{Rp} .48 .70 / \mathrm{Km}$

4. Servis Besar

Oli $\operatorname{mesin}=10$ liter $x$ Rp $26.500=$ Rp $265.000 ;$ Oli gardan $=5$ liter $x$ Rp. $26.400=$ Rp 132.00

Gemuk $=1 \mathrm{~kg} \times \mathrm{Rp} 36.000=\mathrm{Rp} 35.000$; Oli transmisi $=5$ liter $=$ Rp. 165.000

Minyak rem = 1 liter x Rp $90.000=$ Rp. 90.000,- ; Filter oli = 1 buah x Rp 46.000= Rp 46.000-

kanvas rem $=2$ buah $x 150.000=300.000$; head gasket $=175.000 ;$ Kanvas kopling $=360.000$;

filter solar $=25.000$; busi $=4$ buah $\times 25.000=100.000 ;$ Upah servis $=$ Rp 150.000,-

Jumlah = Rp. 1.933.000

Servis besar $=\frac{\text { Biaya servis besax }}{22.176 \mathrm{~km}}=\operatorname{Rp} 87,16 \mathrm{~km}$

5. Cuci Kendaraan

biaya cuci kendaraan mesin rata-rata dari tiap trayek per $1 \mathrm{x}$ cuci

Cuci kendaraan $=\frac{\text { Biaya caci kendaraan/hari }}{\mathrm{km}-\mathrm{tempuh/hari}}=\operatorname{Rp} 378,79 / \mathrm{Km}$

6. Retribusi Terminal

Retribusi $=\frac{\text { Retribusi terminal } / \text { hari }}{\mathrm{Km}-\text { tempuh } / \mathrm{hari}}==$ Rp. $60,60 / \mathrm{km}$

7. KIR

$\mathrm{KIR}=\frac{\text { Biaya KIr/tahun }}{\mathrm{Km}-\text { tempuh/tahurn }}=\mathrm{Rp} 2,70 / \mathrm{km}$

\section{Perhitungan Biaya Tak Langsung}

Biaya tak langsung adalah biaya yang tak dapat langsung dikenakan terhadap operasi perangkutan, tetapi menjadi bagian dari biaya pokok dan unit biaya [4]. Biaya tak langsung dibagi menjadi dua bagian yaitu biaya izin usaha/kendaraan dan biaya izin trayek. Biaya izin usaha/kendaraan (per 5 tahun) sebesar Rp.7.000.000 / kendaraan, sedangkan biaya izin trayek sebesar Rp.800.000,-/kendaraan. 
Total biaya tidak langsung per segmen usaha / tahun $=$ Rp.7.800.000/th, Biaya tidak langsung per bus per tahun ( total biaya tidak langsung per segmen usaha / tahun dibagi jumlah bus / segmen usaha) = Rp.2.600.000/th ; Biaya tidak langsung/bus-km = Rp 117,24/bus-km.

\section{Besaran Biaya Operasi Kendaraan} /kend-km

Dari analisa dan perhitungan di atas dapat diketahui besarnya biaya operasi ke BOK = Rp. 5.100,03

\section{E. Analisa Tarif Berdasarkan BOK}

Perhitungan tarif angkutan umum merupakan hasil perkalian antara tarif pokok dan jarak (kilometer) rata-rata satu perjalanan (tarif Break Event Point) dan di tambah $10 \%$ untuk keuntungan jasa perusahaan [4]. Secara matematis dirumuskan sebagai berikut : Faktor muat penumpang x kapasitas kendaraan, Tarif pokok = total biaya pokok, Tarif BEP $=$ tarif pokok $\mathrm{x}$ jarak rata-rata, Tarif $=$ tarif $\mathrm{BEP}+($ tarif $\mathrm{BEP} \times 10 \%)$. Berdasarkan dari analisa dan perhitungan BOK sesuai SK 687/AJ.206/DRDJ/2002 diatas, dapat dihitung besarnya tarif angkutan umum antar kota teoritis tiap trayek

Tabel 2 Tarif Berdasarkan BOK PO. Teguh Rahayu

\begin{tabular}{|c|c|c|c|}
\hline NO & Hari & Trayek & $\begin{array}{c}\text { Tarif Berdasarkan BOK } \\
\text { (Rupiah) }\end{array}$ \\
\hline 1 & Minggu $10 / 01 / 2021$ & Terminal Purbalingga - Bobotsari & Rp 6.302,04 \\
\hline \multirow[t]{2}{*}{2} & Senin 11 / 01 / 2021 & Terminal Purbalingga - Bobotsari & Rp 5.511,79 \\
\hline & & Rata - rata & Rp 5.906,91 \\
\hline
\end{tabular}

Tabel 3. Perbandingan Tarif Micro Bus PO. Teguh Rahayu Berdasarkan BOK dan Tarif yang Diberlakukan

\begin{tabular}{cccc}
\hline Hari & Trayek & $\begin{array}{c}\text { Tarif Berdasarkan } \\
\text { BOK (Rupiah) }\end{array}$ & $\begin{array}{c}\text { Tarif Yang } \\
\text { Diberlakukan (Rupiah) }\end{array}$ \\
\hline Minggu 10/01/2021 & Terminal Purbalingga - Bobotsari & Rp 6302,04 & Rp 5.000 \\
Senin 11/ 01/2021 & Terminal Purbalingga - Bobotsari & Rp 5.511,79 & Rp 5.000 \\
& Rata - rata & Rp 5.906,91 5.000 \\
\hline
\end{tabular}

\section{F. Tarif Maksimal dan Tarif Minimal}

Tabel 4. Tarif Maksimal dan Minimal.

\begin{tabular}{llc}
\hline No & Batas Tarif & Tarif \\
\hline 1 & Tarif Maksimal & Rp 6.302,04 \\
2 & Tarif Minimal & Rp 3.428,35 \\
& Rata - rata & Rp 4.865,29 \\
\hline
\end{tabular}

\section{G. Evaluasi Tarif}

Evaluasi tarif pada dasarnya dilakukan dengan menggunakan tiga informasi yang telah di peroleh sebelumnya, yaitu berdasarkan besarnya biaya produk operasional, biaya yang diberlakukan dan peraturan kepala Dinas Perhubungan provinsi jawa tengah tentang peraturan tarif batas atas dan batas bawah angkutan umum micro bus antar kota dalam provinsi. Ketiga informasi dasar tersebut digabungkan, mengingat bahwa prinsip dasar dari suatu tarif adalah suatu besaran atau struktur yang mampu mengakomodasi dua kepentingan, kepentingan pemilik angkutan umum dan kepentingan masyarakat sebagai pengguna jasa angkutan umum. Dimana kepentingan pemilik angkutan umum dapat direpresentasikan dengan besaran biaya pokok kendaraan dan biaya yang diberlakukan [1].

Secara ideal, struktur dan besaran tarif yang baik adalah suatu struktur dan besaran tarif yang mampu mengakomodasi kedua kepentingan. Artinya adalah struktur dan besaran tarif yang dimaksud harus dibuat sedemikian rupa sehingga besarannya lebih besar dari biaya operasional kendaraan yang di keluarkan 
pemilik angkutan (dalam hal ini operator) dan juga besarannya masih dibawah biaya yang diberlakukan dan tidak melampaui tarif yang dikeluarkan oleh Pemerintah termasuk saat kondisi dimana jumlah penumpang minimal dengan tarif BEP Rp. 3.116,68.

Tabel 5. Perbandingan Analisis Tarif

\begin{tabular}{lcccc}
\hline No & Analisis Tarif & $\begin{array}{c}\text { Tarif } \\
\text { Berdasakan } \\
\text { BOK (Rupiah) }\end{array}$ & $\begin{array}{c}\text { Tarif DISHUB Prov. } \\
\text { (Rupiah) }\end{array}$ & $\begin{array}{c}\text { Tarif Diberlakukan } \\
\text { (Rupiah) }\end{array}$ \\
\hline 1 & Tarif Maksimal & Rp. 6.302,04 & Rp. 7.300 & Rp. 5000 \\
2 & Tarif Minimal & Rp. 3.428,35 & Rp. 4.500 & Rp. 5000 \\
\hline
\end{tabular}

\section{KESIMPULAN}

Sistem tarif pada Micro Bus PO. Teguh Rahayu yang diberlakukan adalah sistem tarif langsung yang ditetapkan oleh Pemerintah Kabupaten Purbalingga. Dari perhitungan besaran tarif angkutan umum micro Bus PO Teguh Rahayu berdasarkan banyaknya jumlah penumpang pada saat survey diperoleh tarif maksimal sebesar Rp 6.302,04 dan perhitungan tarif minimal sebesar Rp 3.428,35. Sedangkan tarif yang ada diberlakukan PO. Bus Teguh Rahayu saat ini sebesar Rp. 5000/orang-trip, Pengelola usaha masih mendapatkan keuntungan. Dan tarif sudah sesuai dengan ketentuan batas atas - batas bawah yang ditetapkan oleh pemerintah.

\section{DAFTAR PUSTAKA}

[1] Widari, Sri., "Analisis Tarif Angkutan Pedesaan Berdasarkan Biaya Operasional Kendaraan. (Studi Kasus Kabupaten Gayo Lues Nanggroe Aceh Darussalam)", http://e-journal.uajy.ac.id/, 2010.

[2] T. M. Ridwan, "Studi Penentuan Tarif Penumpang Angkutan Bus Sedang (Studi Kasus Trayek LhokseumaweBireuen)", Teras Jurnal, Vol 3, No 2, September 2013.

[3] Fajar Arif Pamuji "Analisis Tarif Angkutan Antar Kota Berdasarkan Biaya Operasional Kendaraan (BOK) dari kota Stabat-Binjai”, http://repository.umsu.ac.id, 2020.

[4] Warpani, Suwardjoko, "Pengelolaan Lalu Lintas dan Angkutan Jalan", Institut Teknologi Bandung, Bandung, 2002. 